\title{
Physiological Significance of Lysophospholipids that Act on the Lumen Side of Mammalian Lower Digestive Tracts
}

\author{
Akira Tokumura* \\ Department of Pharmaceutical Health Chemistry, Institute of Biosciences, University of Tokushima Graduate School, 1-78-1 \\ Shomachi, Tokushima 770-8505, Japan
}

(Received November 26, 2010)

\begin{abstract}
The lysophospholipid mediator family is attracting increased attention for its role in the maintenance of human health and the prevention and treatment of human chronic diseases. This review focuses on recent findings about lysophosphatidic acid (LPA) and its potential precursor phospholipids present in the apical lumen of mammalian lower digestive tracts. In particular, information on the protective effect of LPA toward rat gastric mucosa allowed us to better understand the mechanisms of the gastric ulcer-protective effect of a Chinese medicine and the beneficial effects of intake of vegetables and/or soybean lecithin in foods. These findings may indicate that LPArich foodstuffs promote human health by regulating the integral and functional homeostasis of the gastrointestinal mucosa, although the safety of LPA supplementation should be intensively investigated further.
\end{abstract}

Key words — lysophospholipid mediator, lysophosphatidic acid, gastric ulcer, mucosa protection

\section{INTRODUCTION}

Human intestinal epithelial cells are subjected to injurious stimuli such as toxic bacteria and substances in foods on the apical lumen side and released into the basolateral interstitium from the blood circulation on the basolateral side. Natural foods carry potentially active components that prevent injury by harmful chemicals and bacteria and regulate multiple functions in the digestive tract. Food-derived lipids, especially complex lipids, are also capable of affecting gastrointestinal functions. In addition, the digestion tract releases several types of bioactive lipids together with polypeptide hormones into the lumen. Thus, gastrointestinal immunity and inflammation are known to be affected by both dietary lipids and lipid metabolism in the digestive tract. ${ }^{1)}$ In addition, luminal products of digestion including lipids act as modulators of secretion of bioactive hormones from enteroendocrine cells. For instance, one of the $N$-acylethanolamines, oleoyl-ethanolamine, which is released from the gut

\footnotetext{
*To whom correspondence should be addressed: Department of Pharmaceutical Health Chemistry, Institute of Biosciences, University of Tokushima Graduate School, 1-78-1 Shomachi, Tokushima 770-8505, Japan. Tel.: +81-88-633-7248; Fax: +81-88-633-9572; E-mail: tokumura@ph.tokushima-u.ac.jp
}

after meals, has been proposed as a novel type of anorexic mediator. ${ }^{2)}$ The feeding-dependent mobilization of oleoyl-ethanolamine is confined to the mucosal layer and not observed on the serosal layer of the duodenal and jejunum walls. ${ }^{3)}$

In addition to well-known fatty acid-derived mediators such as eicosanoids, complex lipid mediators possessing one long hydrophobic chain in the digestive system have recently attracted much attention. First, modulation of gastrointestinal wound repair and inflammation by mucus phospholipids has been well addressed. ${ }^{4)}$ Second, lysophosphatidic acid (LPA, 1 or 2acyl-sn-glycerol-3-phosphate; Fig. 1), an important member of the phospholipid mediator family that includes platelet-activating factor (1-Oalkyl-2-acetyl-sn-glycero-3-phosphocholine), ${ }^{5)}$ has attracted much attention as a novel modulator of intestinal wound healing. ${ }^{4)}$ At present, at least six $\mathrm{G}$ protein-coupled receptors (GPCR) specific for LPA have been characterized. ${ }^{6-8)}$ GPR 35 , an orphan GPCR that was shown to be expressed in the intestinal lumen and postulated to participate in the development of gastric cancer, ${ }^{9)}$ has recently been shown to respond more specifically to polyunsaturated LPAs than to kynurenic acid. ${ }^{10)}$ Lysophosphatidylinositol (LPI, Fig. 2), lysophos- 


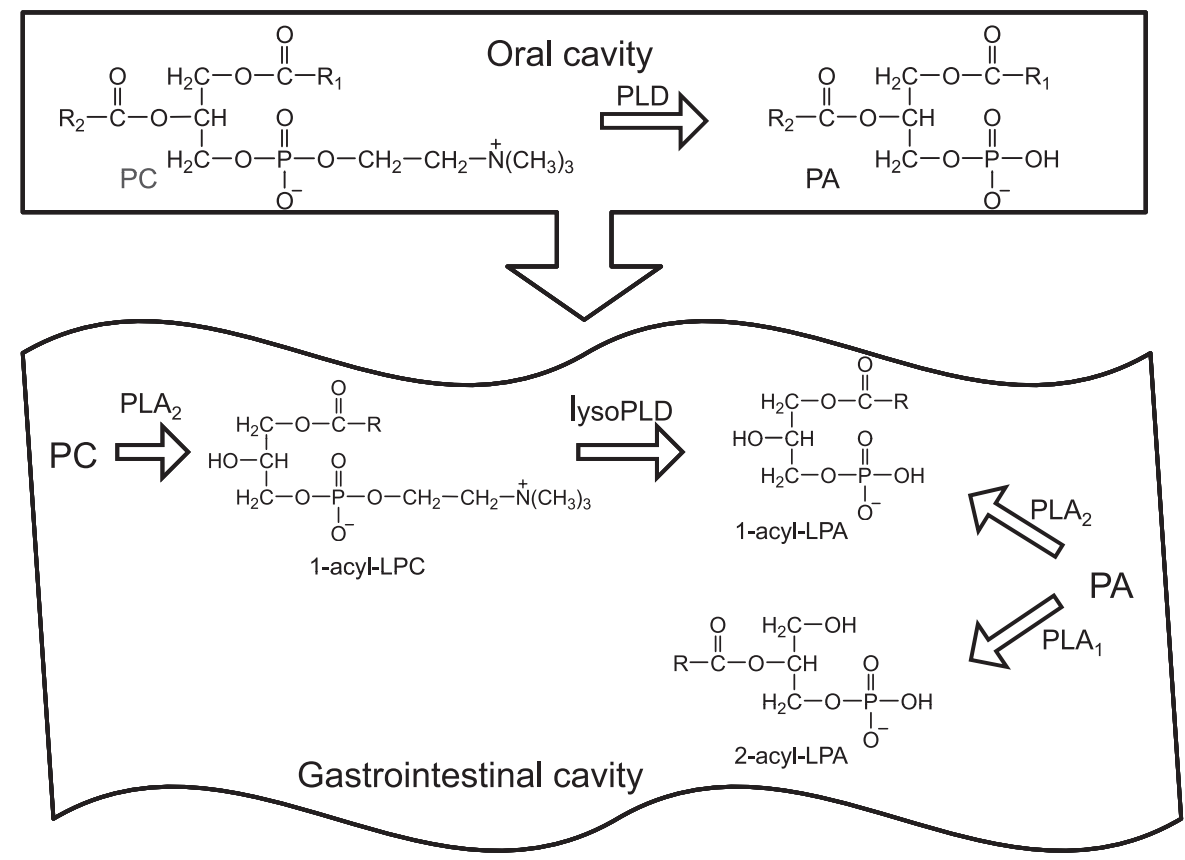

Fig. 1. Possible Metabolic Pathways of LPA Production in Mammalian Digestive Tracts

Abbreviations used are: LPA, lysophosphatidic acid; LPC, lysophosphatidylcholine; PC, phosphatidylcholine; PA, phosphatidic acid; RCOOH, fatty acid.
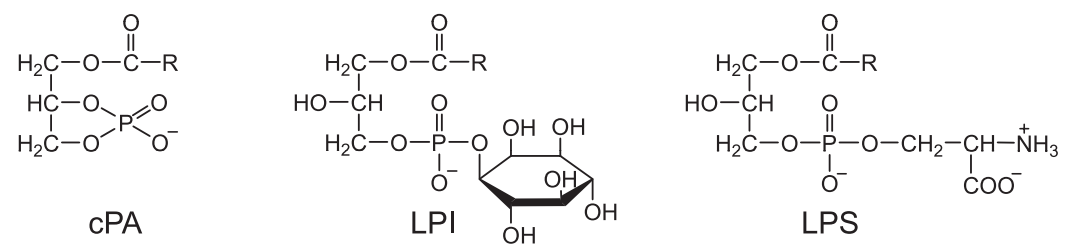

Fig. 2. Members of Lysophospholipid Mediator Family

The structures of LPI and LPS are shown representatively as 1-acyl isomers, respectively.

phatidylserine (LPS, Fig. 2) and sphingosine 1phosphate (S1P, Fig. 3), binding specifically to four GPCR $\left(\mathrm{LPS}_{1} / \mathrm{GPR} 34, \mathrm{LPS}_{2} / \mathrm{P} 2 \mathrm{Y} 10, \mathrm{LPS}_{3} / \mathrm{RIK}\right.$, $\left.\mathrm{LPS}_{4} / \mathrm{GPR} 174\right)$, one GPCR (GPR55) and five GPCR $\left(\mathrm{S}_{1} \mathrm{P}_{1}, \mathrm{~S}_{1} \mathrm{P}_{2}, \mathrm{~S}_{\mathrm{P}} \mathrm{P}_{3}, \mathrm{~S}_{\mathrm{P}} \mathrm{P}_{4}, \mathrm{~S} 1 \mathrm{P}_{5}\right)$, respectively, are grouped with LPA into the lysophospholipid mediator family. ${ }^{11,12)}$ Several $\mathrm{pH}$-sensitive GPCR (OGR1, GPR4, G2A) have been suggested to be specific for lysophosphatidylcholine (LPC, Fig. 1) and or its analog having a sphingosine backbone, sphingosylphosphorylcholine (SPC), but the original papers showing the direct agonistic effects of LPC and SPC to GPR4 and OGR1 have been retracted, and the behavior of LPC as a ligand to G2 is still a matter of debate. ${ }^{13)}$ In this review, I will focus on the physiological and pathophysiological roles of the lysophospholipid mediators, especially LPA and LPC, derived from foodstuffs or released from the mucosal layer of the gastrointestinal wall. These lysophospholipids, which are present in foods, produced in the lumen of the lower digestive tract, or released from digestive mucosa, are capable of acting directly on the lumen surface for maintenance of the mucosal structural integrity and functional homeostasis.

The fatty acyl moieties of phospholipids are designated in terms of the number of carbon atoms and double bond as follows: $16: 0$, palmitoyl group; $18: 0$, stearoyl group; $18: 1$, oleoyl group; $18: 2$, linoleoyl group; $18: 3, \alpha$-linolenoyl.

\section{FOODS AND GASTROINTESTINAL HOMEOSTASIS}

Foods such as meat, eggs and fish as well as soyderived foods contain significant amounts of sphingomyelin (SPM, Fig. 3). ${ }^{14-16)}$ The physiological 


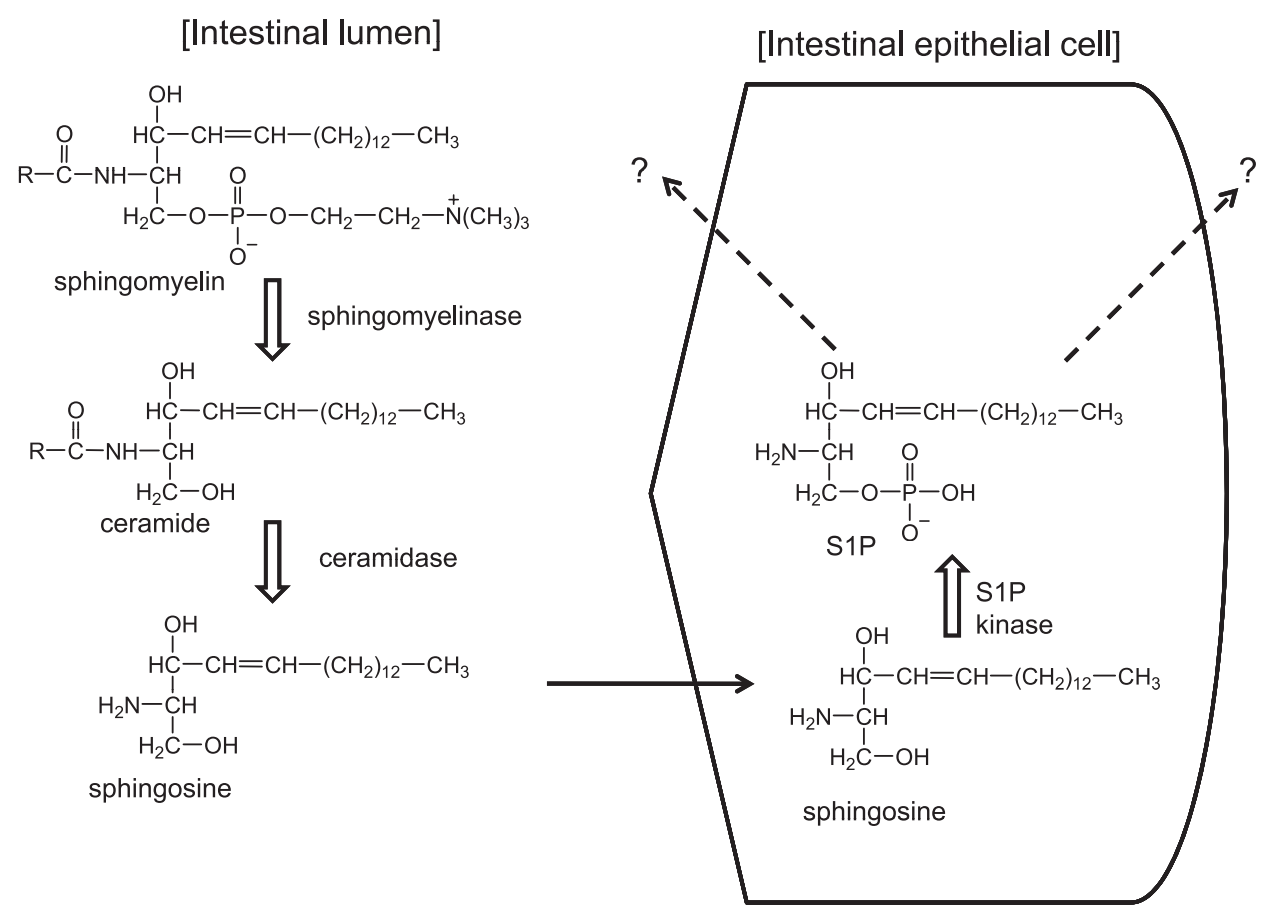

Fig. 3. Possible Metabolic Pathways for Dietary Sphingomyelin in Mammalian Digestive Tracts

roles of SPM and its metabolites (ceramide and sphingosine, Fig. 3) in foods have recently been well recognized. ${ }^{17,18)}$ However, there has been no extensive investigation of S1P, a lysophospholipid mediator that exerts diverse physiological effects in mammals, in foods and mechanisms for its intestinal intake and subsequent metabolism. In contrast to the sphingosine-backboned phospholipids, the glycerol-based phospholipids that have two long chain acyl groups [phosphatidylcholine (PC), phosphatidylethanolamine (PE), phosphatidylinositol (PI), and phosphatidylserine (PS)] in different foods are well studied, ${ }^{19-21)}$ as are the mechanisms of their absorption into the bodies of mammals. ${ }^{22)}$ However, fewer investigations on both the physiological effects and intestinal absorption of glycerol-based lysophospholipids have been reported. Although both LPC and phosphatidic acid (PA, Fig. 1), precursors of bioactive LPA, are reported to be present in foods, there are few reports showing the presence of acidic lysophospholipids in foods. For instance, lysophosphatidylethanolamine (LPE) is known to comprise $5 \%$ of total phospholipids in human milk. ${ }^{23)}$ The soy-protein isolates used for preparation of soy-based infant formula contain significant amounts of lysophospholipids such as LPC, LPA, LPE, LPI and lysophosphatidylglycerol. ${ }^{24)}$ At the end of $1970 \mathrm{~s}$, a sig- nificant amount (about $0.1 \%$ ) of LPA in soybean lecithin was identified as a vasopressor substance. ${ }^{25}$ ) Since then, the investigation of food-derived LPA was not extended until that a micromolar concentration of LPA was shown to be present in hen egg yolk and white. ${ }^{26)}$ Interestingly, hen egg yolk contains mainly saturated and monounsaturated molecular species, whereas polyunsaturated species are predominant in hen egg white. ${ }^{26)} \mathrm{Re}$ cently, various types of vegetables including cabbage leaf have been demonstrated to contain significant amounts of LPA. ${ }^{27)}$ Cabbage leaf was the richest vegetable source of LPA, the major molecular species of which were $\alpha$-linolenate $(18: 3)$ containing species followed by palmitate (16:0)-, linoleate $(18: 2)$ - and oleate $(18: 1)$-containing species in that order. ${ }^{27)}$

\section{DIGESTION OF GLYCEROLIPIDS AND SPHINGOLIPIDS}

The predominant glycerophospholipid in the intestinal lumen is PC, and its digestion is mainly carried out by pancreatic phospholipase $\mathrm{A}_{2}\left(\mathrm{PLA}_{2}\right)$ and other lipases to produce LPC and free fatty acids. The high monoacylglycerol lipase expression in the intestinal epithelia of the rat small intestine is sug- 
gestive of its digestive role. ${ }^{28)}$ Reduced digestion of phospholipids by a PLA 2 inhibitor, FPL67047XX, retarded cholesterol absorption. ${ }^{29)}$ Because the cholesterol absorption efficacies of $\mathrm{PLA}_{2}(+/+)$ and $\mathrm{PLA}_{2}(-/-)$ mice were similar, however, phospholipase B located in distal intestine ${ }^{30}$ ) would participate in the phospholipid digestion to compensate for malfunction of pancreatic $\mathrm{PLA}_{2} \cdot{ }^{29}$ ) While mice with targeted inactivation of the group IB PLA 2 gene were reported to show no significant abnormality when raised on a chow diet, ${ }^{29)}$ the $\mathrm{PLA}_{2}$ deficient mice fed a high-fat diet displayed lower postprandial glycemia than wild-type mice, causing a decreased level of plasma LPC. ${ }^{31)}$ The reduced plasma LPC level would enhance insulinmediated glucose metabolism, leading to protection from postprandial hyperglycemia. ${ }^{32)}$ Also, the feces from $\mathrm{PLA}_{2}$-deficient rats fed a high-fat diet contained higher amounts of triacylglycerol than those of control rats fed the high-fat diet, ${ }^{31)}$ suggesting the micelle-forming effect of lysophospholipids in the aid of digestion of triacylglycerol. The above hypothesis was demonstrated using differentiated enterocyte-like Caco-2 cells exposed apically to mixed micelles containing LPC. ${ }^{33)}$ Less is known about the absorption mechanism and enzymes of other diacyl phospholipids such as PE, PS and PI. In addition, few reports have been published on the absorption of the alkylacyl and alkenylacyl subclasses of PC and PE. Interestingly feeding a diet containing bovine brain plasmalogens, the alkenylacyl subclass of PC and PE, increased the concentration of plasmalogens three fold in the blood plasma of rats, suggesting that a significant percentage of dietary plasmalogen is absorbed from the intestine after escaping degradation by acid in the stomach. ${ }^{34)}$

Alkaline sphingomyelinase expressed on the intestinal mucosa was shown to permit digestion of dietary SPM ${ }^{17)}$ (Fig. 3). Neutral ceramidase, which is highly expressed in the small intestine along the brush border, was found to be essential for the intestinal degradation of sphingolipids in mice ${ }^{35}$ ) (Fig. 3). Dietary SPM was reported to alleviate the experimental bowel disease induced by dextran sodium sulfate in mice, by reducing inflammatory reactions possibly induced by its degradation products, ceramide and sphingosine. ${ }^{36)}$ Alkaline sphingomyelinase activity in the colon biopsies was significantly lower in the patient group with longstanding colitis compared with controls. ${ }^{37)}$

\section{PC CONCENTRATIONS IN DIGESTIVE TRACTS}

The apical lining of extracellular phospholipids in the gastrointestinal tract is the first line of protection for mucosal integrity. PC is a major phospholipid in the gastrointestinal mucus, and it forms aggregates at the luminal surface of the digestive tract, thus protecting the intestinal epithelium from injurious food components and bacterial pathogens. Evidence for PC secretion in the luminal mucus of rat digestive tracts was reported; the concentration was the highest in the ileum, lower in the jejunum and minimal in the colon. ${ }^{38)}$ Luminal applications of PC and LPC were reported to exert an anti-inflammatory effect on rat intestinal mucosa by reducing the up-regulation of proinflammatory cytokines induced by tumor necrosis factor- $\alpha$ (TNF$\alpha)$ /nuclear factor $\kappa \mathrm{B}$, possibly through its incorporation into the lipid raft of the plasma membranes. ${ }^{39)}$ The shift in the phospholipid composition of the gastric mucus toward an increased ratio of LPC to PC might be induced by $\mathrm{PLA}_{2}$ activity in humans infected with Helicobacter pylori, and thus impair the ability of the barrier to protect against bacterial pathogens and high-molecular weight components in foods. ${ }^{40)}$ Pretreatment with PC with one or two polyunsaturated fatty acyl groups prevented cold restraint stress-induced ${ }^{41)}$ and ethanol- and indomethacin-induced gastric ulcers in rats. ${ }^{42)}$ Furthermore, PC prevented gastrointestinal mucosal injury induced by acetic acid, ${ }^{43)}$ bile acid, ${ }^{44)}$ trinitrobenzene sulfonic acid ${ }^{45)}$ and aspirin. ${ }^{46)}$ Patients with ulcerative colitis had lower concentrations of PC and LPC in the rectal mucus than patients with Crohn's disease and control subjects, ${ }^{47)}$ and oral administration of PC in a delayed release mode was beneficial for chronic ulcerative colitis. ${ }^{47,48)} \mathrm{PC}$ in the mucus has an anti-inflammatory effect, and the mucus layer of patients with ulcerative colitis was characterized by a low level of PC. ${ }^{47,48)}$ Indeed, exogenous PC induced actin assembly, activation of mitogen-activated protein kinases, transport of nuclear factor- $\kappa \mathrm{B}$ subunits, and up-regulation of proinflammatory genes in Caco- 2 cells, ${ }^{49)}$ and PC was effective in the protection of Caco-2 cells from activation by Escherichia coli K12- or TNF- $\alpha$, when it was added to a Caco-2 cell monolayer on the apical side. ${ }^{50)}$ Crohn's disease and ulcerative colitis are diffuse types of chronic gastrointestinal inflammatory diseases with high mortality rates, and thus they are a major health problem around the world. Al- 
though many studies of the mucosa-protective effects of PC secreted into the digestive lumen have been performed, there are relatively fewer investigations of its metabolism in the lumen and beneficial effects of the metabolites.

\section{DOES LPC EXERT GASTROINTESTINAL MUCOSA-INJURING OR PROTECTING FACTOR?}

The concentration of LPC in the luminal contents of human intestinal fluid collected from the proximal jejunum was increased more than $2.5 \mathrm{mM}$ after a single-pass in vivo perfusion of a fatty meal. ${ }^{51)}$ The concentration of LPC in rat gastric fluid increased in the range of $0.5-1 \mathrm{mM}$ with time up to $5 \mathrm{hr}$ after intraperitoneal administration of lipopolysaccharide, concomitant with a much lower increase in the intestinal fluid, suggesting a protective mechanism in the rat intestine for treatment with lipopolysaccharide. ${ }^{52)}$ Unfortunately, the physiological significance of LPC in the gastrointestinal lumen in mammals remains largely unknown at present. A recent investigation suggested that LPC plays a physiological role in host-defense mechanisms in the brush-border apical membranes of Caco-2 cells and rat jejunum because it stimulated the release of glycosylphosphatidylinositolanchored alkaline phosphatase that dephosphorylates the toxic lipopolysaccharides from the membranes. ${ }^{53)}$ In this case, the released alkaline phosphatase might still be able to play a physiological role in the colonic lumen. On the other hand, LPC is known to induce mucosal damage in the stomach $^{54-56)}$ and colon. ${ }^{57)}$ Group X secretory PLA 2 $\left(\mathrm{SPLA}_{2}\right)$ was shown to stimulate the proliferation of colon cancer cells (Colon-26) by producing various lipid mediators including LPC and arachidonic acid. ${ }^{58)}$ On the other hand, the production of LPC was suggested not to be involved in intestinal injury after ischemia and reperfusion stress in mice, but rather production of prostaglandin $\mathrm{E}_{2}$ participated in the intestinal damage. ${ }^{59)}$ At high concentrations LPC impaired the mucosal barrier function and increased gastrointestinal permeability in isolated rat ileum, ${ }^{60)}$ rat stomach, ${ }^{61)}$ rat intestine, ${ }^{62)}$ guinea-pig proximal jejunum ${ }^{63}$ ) and human intestinal cells. ${ }^{64)}$ Intraduodenally injected lipopolysaccharide induced the release of $\mathrm{SPLA}_{2}$, increasing the luminal level of LPC in rats, ${ }^{52)}$ although LPC was found to be protective when injected intravenously in rats. ${ }^{65)}$

Interestingly, pancreatic sPLA 2 IB, which generates both fatty acids and lysophospholipids is expressed in mouse ${ }^{66)}$ and rat $^{67)}$ gastric mucosa, and Helicobacter pylori infection decreased the $\mathrm{PLA}_{2}$ activity in the glandular stomach of the C57BL/6 mouse, suggesting reduction of cytoprotective prostaglandins. ${ }^{66)}$ High expression of sPLA $_{2}$ II in the colon mucosa of patients with Crohn's disease and ulcerative colitis was also reported. ${ }^{68,69)}$

\section{POTENTIAL PRESENCE OF LPA IN LUMEN OF MAMMALIAN DIGESTIVE TRACTS}

Soybean lecithin was reported to contain about $0.1 \%$ LPA, consisting of molecular species having a polyunsaturated fatty acyl groups such as $50.0 \%$ $18: 2,24.7 \% 16: 0,7.5 \%$ stearic acid (18:0), $8.7 \%$ $18: 1$ and $7.0 \% 18: 3{ }^{25)}$ LPA is likely to be formed in the lumen of the gastric tract by two potential metabolic routes, as shown in Fig. 1. The first is the degradation of PA by phospholipase $\mathrm{A}_{1}\left(\mathrm{PLA}_{1}\right)$ and $\mathrm{PLA}_{2}$. At present, little is known about PA in ordinary foods, however, there is one systematic study of LPA concentrations in various foodstuffs including cabbage leaf. ${ }^{27)}$ The authors showed that mastication of fresh cabbage leaves in the human mouse caused the net productions of $195 \mathrm{nmol} / \mathrm{g}$ wet weight of PA and $22 \mathrm{nmol} / \mathrm{g}$ of LPA due to the release of potent phospholipase $\mathrm{D}$ activity toward cabbage phospholipids and lysophospholipids, respectively. ${ }^{27)}$ The PA flows down to the stomach where it might be converted to LPA by $\mathrm{PLA}_{1}$ or PLA 2 activity, because pancreatic $\mathrm{PLA}_{2}$ significantly converted PA in a lipid extract from cabbage leaves to LPA, a wound-healing factor, when they were incubated in the lumen of isolated mouse stomach. ${ }^{27)}$ The authors suggested that the gastric mucosa protective effect is mediated not only by methylmethionine sulfonium chloride, formerly called vitamin $\mathrm{U},{ }^{70)}$ but also by LPA, which is known as a woundhealing factor in animal skin and intestinal mucosa. The two isoforms of PA-specific PLA 1 (mPA-PLA 1 $\alpha /$ LIPH and $\beta /$ LIPI) characterized to date are extracellular in their catalytic properties. ${ }^{71}$ The former isomer is abundantly expressed in the human colon, but not the small intestine. A recent paper sug- 
gested that Group III sPLA 2 is not only a biomarker, but also therapeutic target molecule of human colon cancer. ${ }^{72)}$ Whether mPA-PLA $1 \alpha$ or PLA 2 III participates in the conversion of PA to LPA in the lumens of animal gastrointestinal tracts in vivo remains to be explored further.

The second possible pathway for LPA production in the gastrointestinal lumen is degradation of lysophospholipids by secretory or ecto-type lysophospholipase D (lysoPLD) activity (Fig. 1). The extracellular enzymatic conversion of LPC to LPA was first investigated in secretory lysoPLD activity in rat plasma, ${ }^{73)}$ and later in plasma or serum from different animals and several biological fluids including human peritoneal fluid including malignant ascites, human urine, human follicular fluids, human and dog cerebrospinal fluids, human blister fluid and hen egg white were studied. ${ }^{74-76)}$ Autotaxin (ATX), the second member of the ecto-nucleotide pyrophosphatase/phosphodiesterase family, was originally isolated from human A 2058 melanoma cells as a tumor cell mobility-stimulating protein. ${ }^{77)}$ Later, lysoPLD activities that convert LPC to LPA in human plasma ${ }^{78)}$ and fetal calf serum ${ }^{79)}$ were both found to be due to ATX, supporting the pathophysiological significance of LPA as a tumor-aggression factor. To our knowledge, no study has reported a significant release of ATX into the lumens of mammalian gastrointestinal tracts. In this context, it should be mentioned that the mouse adenocarcinoma cell line Colon-26 cells released no lysoPLD activity due to ATX ${ }^{58)}$ Furthermore, LPA produced by ATX/lysoPLD enhanced the intestinal cell motility of undifferentiated Caco- 2 cells by the formation of lamellipodia and redistribution of villin to the cell surface. ${ }^{80)}$ Unlike LPA, cyclic phosphatidic acid (Fig. 2) and its carba analogs inhibited the bombesin-stimulated metastatic effects in azoxymethane-induced intestinal cancers in rats. ${ }^{81)}$ The carba analogs were found to inhibit the lysoPLD activity of ATX, and thus inhibit cancer cell invasion. ${ }^{82)}$

\section{LPA ACTS AS WOUND-HEALING AND MUCOSA-PROTECTING FACTOR}

As suggested above, LPA present in foods or produced in the upper digestive tract and stomach may prevent gastrointestinal ulceration and inflammatory colitis, and accelerate the healing of lesions.
The first indication was drawn from a study showing that a soy-derived anti-apoptotic fraction protected rat gastrointestinal epithelium from damage caused by methotrexate treatment. ${ }^{83)}$ Later, LPA reportedly enhanced migration and inhibited proliferation of the intestinal epithelial cell line- $6,{ }^{84)}$ and intrarectal injection of LPA ameliorated intestinal epithelial injury induced by instillation of trinitrobenzene sulfonic acid for induction of colitis. ${ }^{85}$ ) This hypothesis was supported by in vitro experiments with the cultured human gastric cell line RGM-1 showing that LPA at $10 \mathrm{ng} / \mathrm{ml}$ increased cell migration. ${ }^{86)}$ An early investigation showed that LPA induced the restitution of isolated guinea-pig gastric mucosa preparation impaired by genistein. ${ }^{87)}$ Consistent with early reports, Tanaka et al. showed that $18: 1$ LPA and cabbage leaf-derived LPA increased cell migration after wounding in a cultured monolayer of the human gastric cell-line, HGC-27, suggesting wound healing by LPA of gastric mucosa in vivo. ${ }^{27)}$ This suggestion was confirmed by a recent in vivo study showing that intragastric administration of a dispersion of standard LPA decreased the gastric ulcer index with the following potency order $(18: 2$ LPA $=18: 3$-LPA $>18: 1$-LPA) in rats under water immersion restraint stress. ${ }^{88)}$ They showed that intragastric injection of partially purified LPA $(32.1 \%$ of total phospholipids) from soybean lecithin produced a biphasic effect on the stress-induced gastric ulcer in rats. At low concentrations of 0.001 and $0.01 \mathrm{mM}$ LPA enriched in unsaturated species (46.2, 10.3 and $5.7 \%$ for $18: 2-, 18: 1$ and $18: 3$-species, respectively) induced $30-40 \%$ inhibition of the water immersion restraint stress-induced gastric ulcers, whereas at concentrations above $0.03 \mathrm{mM}$ there was no significant effect on the gastric ulcer index. Further purification of LPA resulted in a monophasic concentration-dependent inhibition, suggesting the removal of components that may aggravate gastric ulcer. This result indicates that purification of LPA from soybean lecithin is an advance in the development of effective anti-gastric ulcer supplements.

Antyu-san is a Chinese medicine that is used to treat ulcers of the stomach and duodenum. The medicine comprises licorice root, amomum seed, fennel, oyster shell, cinnamon bark, lesser galangal and corydalis tuber, the last of which was found to contain significant amounts of LPAs $(14.7,12.8$, 5.1 and $1.9 \mathrm{nmol} / \mathrm{g}$ of $18: 2,16: 0,18: 1$ and $18: 3$ species, respectively). As expected, intragastric administration of a solution of six dried component of antyu-san without corydalis tuber showed a lower 
ulcer-protecting activity than that by a solution of all seven components of antyu-san. ${ }^{88)}$ These results suggest that corydalis tuber is the main component involved in the gastric ulcer-inhibitory effect of antyu-san, and that LPA plays the central role in the ulcer-preventive activity of antyu-san.

There are several reports documenting the effects of LPA on intestinal functions other than its mucosa-protective effect. LPA was reported to prevent cholera toxin-induced secondary diarrhea in mouse intestine by inhibiting cystic fibrosis transmembrane conductance regulator (CFTR)dependent $\mathrm{Cl}^{-}$channel activity through its binding to $\mathrm{LPA}_{2}{ }^{89)}$ Furthermore, $\mathrm{Na}^{+} / \mathrm{H}^{+}$exchanger regulatory factor 2 (NHERF2) was exerted to couple $\mathrm{LPA}_{2}$ and CFTR co-expressed in mouse duodenal crypts. ${ }^{89,90)}$ On the other hand, $\mathrm{LPA}_{5}$ is involved in LPA-mediated fluid absorption through stimulation of the $\mathrm{Na}^{+} / \mathrm{H}^{+}$exchanger 3 (NHE3) in the intestinal brush border from mice. ${ }^{91)}$ This LPA effect would be related to the previous finding that LPA cured diarrhea induced by cholera toxin. ${ }^{89)}$ In fact, $\mathrm{LPA}_{5}$ mRNA is highly expressed in the tip of the villus of mouse brush border. ${ }^{12)}$ Treatment of Caco2 cells with $100 \mu \mathrm{M}$ LPA significantly stimulated apical $\mathrm{Cl}^{-} / \mathrm{OH}^{-}$exchange activity via $\mathrm{LPA}_{2}$ in a phosphatidylinositol-3 kinase/Akt-dependent fashion that may contribute to the anti-diarrheal effects of LPA. ${ }^{92)}$ Interestingly, when LPA was added to the apical and basolateral mediums in a Transwell chamber with a monolayer of undifferentiated Caco-2 cells, both sides stimulated the apical anion exchange. ${ }^{92)}$ LPA was shown to stimulate NHE3 activity in polarized epithelial cells of the brush border (OK cells) stably expressing NHERF2, both delivering NHE3 to the apical domain by a phosphatidylinositol 3-kinase-dependent process and by dissociating NHE3 from NHERF-2 (Fig. 4). ${ }^{93)}$ LPA was also reported to effectively protect intestinallydifferentiated Caco-2 cells from etoposide-induced apoptotic death. ${ }^{94)}$

In mouse ileum and colon as well as a mouse intestinal cell line (IEC6), expression of mRNA of $\mathrm{LPA}_{1}$ was the most abundant, followed by that of $\mathrm{LPA}_{5}$, and significantly less expression was observed for $\mathrm{LPA}_{4}, \mathrm{LPA}_{3}$ and $\mathrm{LPA}_{2} .{ }^{95)} \mathrm{LPA}_{5}$ was suggested to function as the sensory factor on the apical surface of intestinal enterocytes, that responds to dietary intake and regulate fluid absorption as part of normal physiological response to a meal. ${ }^{91)} \mathrm{LPA}_{2}$ was reported to be required patho-physiologically for the protection against radiation-induced intesti-

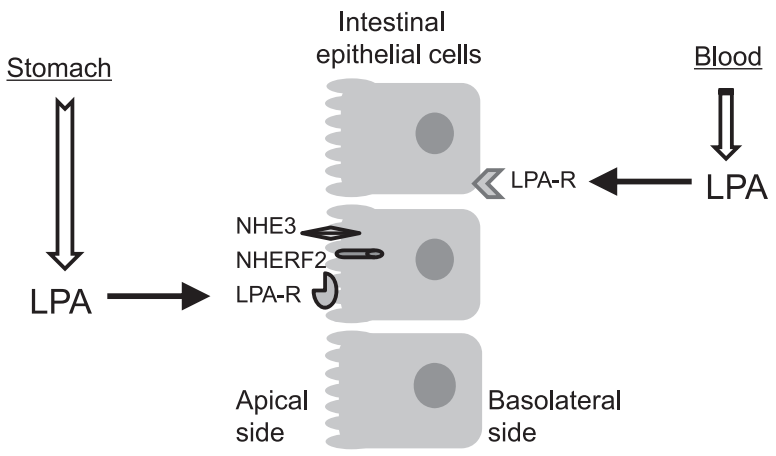

Fig. 4. A Hypothetical Scheme for Bidirectional Actions of LPA in an LPA Receptor-mediated Manner

nal injury. ${ }^{96)}$ However, high expression of $\mathrm{LPA}_{2}$ mRNA on different human colon cancer cells has been reported. ${ }^{97,98)}$ The absence of $\mathrm{LPA}_{2}$ was found to attenuate the formation of tumors in an experimental model of colitis-associated cancer, and LPA orally administrated for four weeks promoted colonic tumor progression in mice heterozygous for the adenomatous polyposis coli allele, but not in wild type mice. ${ }^{98)}$ GPR92/93 was first proposed as a nutrient-sensitive G-protein-coupled receptor secreting cholecystokinin from an enteroendocrine cell line (STC-1), because a protein hydrolysate activates this receptor as well as LPA. ${ }^{12)}$ Subsequently, GPR92/93 was demonstrated to be the fifth LPA receptor $\left(\mathrm{LPA}_{5}\right)$ which is highly expressed in the small intestine in mouse ${ }^{99)}$ and human tissues. ${ }^{100)}$ The latter study that showed $\mathrm{LPA}_{5}$ is highly concentrated in gastrointestinal lymphocytes. ${ }^{100)}$ The P2Y5 transcript is expressed at a similar level along the proximal to distal rat intestinal mucosa, but the expression in the villus tip is two times higher than in the crypt region, suggesting that the LPA receptor $\left(\mathrm{LPA}_{6}\right)$ contributes to intestinal cell adhesion. ${ }^{101)}$ The absence of $\mathrm{LPA}_{2}$ decreased the number and size of intestinal adenoma, suggesting that LPA promotes the progression of intestinal tumor in mice heterozygous for the adenomatous polypopsis coli allele $\left(\mathrm{Apc}^{\mathrm{Min} /+}\right){ }^{98)}$

\section{PATHOPHYSIOLOGICAL ROLE OF LPA IN DIGESTIVE TRACTS}

Soybean lecithin containing about $0.1 \%$ LPA is used extensively as an emulsifier in commercial oils and fatty foods and is believed to be safe for human consumption. Orally injected LPA from 
purified soybean lecithin and a Chinese medicine (antyu-san) showed beneficial effects on the gastric mucosa of rats. ${ }^{88)}$ To understand the functionality of the bioactive phospholipids and evaluate their safety as a major component in food supplements, herbs and Chinese medicines, the patho-physiological effects should be first examined experimentally in animal models. For instance, an in vivo experiment with Wistar rats showed that repeated intraperitoneal injections of LPA for about 30 weeks (one injection every day) resulted in an increased incidence of peritoneal and pleural metastases from intestinal adenocarcinomas induced by azoxymethane. ${ }^{102)}$ Several studies showed that LPA acts as an anti-apoptotic factor toward several colonic cancer cells. ${ }^{103,104)}$ Ablation of $\mathrm{LPA}_{2}$ resulted in increased colonic cancer formation in azoxymethane- and sodium dextran sulfateinduced colitis in mice, ${ }^{98)}$ and decreased tumor progression in $\mathrm{Apc}^{\mathrm{Min} /+}$ mice. ${ }^{95)}$ Participation of the $\mathrm{LPA}_{2}$ receptor has been proposed in human gastric cancer, especially the intestinal type, ${ }^{105)}$ and induced invasion of human gastric cancer cells, AGS, through LPA receptor-mediated up-regulation of the urokinase-type plasminogen activator receptor. ${ }^{106)}$ Further work is necessary to evaluate the balance between the gastric mucosa-protective and gastric tumor-aggravating effects of LPA in human the gastric lumen.

\section{PHYSIOLOGICAL AND PATHOPHYSIOLOGICAL ROLES OF LYSOSPHINGOPHOSPHOLIPIDS}

Little is known about the physiological roles of lysosphingophospholipids such as S1P and SPC in the digestive system. On the other hand, S1P was shown to play a patho-physiological role stimulating proliferation in Caco-2 intestinal epithelial cells 107) and a dextran sulfate sodium-induced mouse colitis model. ${ }^{108)}$ A recent investigation showed that S1P protected intestinal epithelial cells from apoptosis via an Akt-dependent pathway. ${ }^{109)}$ However, there has been no report showing whether S1P and SPC exert a significant effect from the apical side of the gastrointestinal tracts. Also, no systematic work on the concentrations of S1P and SPC in ordinary foodstuffs and Chinese medicines, as well as their potential formations in the lumen of the lower digestive tract of mammals has been reported.

\section{CONCLUDING REMARKS}

The study field of bioactive phospholipids acting on the gastrointestinal mucosa has grown through the past 10 years. In particular, lysophospholipid mediators such as LPA have attracted increasing interest. Several antagonists of LPA receptors were shown to be effective in experimental animals, suggestion that LPA receptors are new therapeutic molecular targets for some types of human diseases including cancer metastasis. ${ }^{110)}$ However, owing to the complexity of differential affinities of LPA receptors to test compounds and incompleteness in the blocking of LPA actions by single LPA antagonist candidates, another approach has also been tried to regulate LPA actions in the human body. This is a rapid advance in the area of drug development research to reduce the circulating and/or local levels of LPA and thus its effects by inhibiting the LPA-producing enzyme activity of ATX. ${ }^{111)}$ The reported candidates include natural food products such as flavonols. ${ }^{112)}$ Compared with the rapid development of pharmaceutical studies on LPA, however, less attention has been paid to LPA homologs and analogs for development as effective components of foodstuffs, especially supplements in functional foods. As shown in this review, evidence is accumulating that lysophospholipids such as LPA and LPC in the lumen of the lower digestive tract have important physiological effects, although most of the effects of LPA are the opposite of those of LPC. Unfortunately, little is known about the presence and function of other lysophospholipids (LPS, LPI and LPE) in the digestive lumen. In addition, recent reports discussed in this review suggest that the LPA receptors expressed on the lumen surface of the lower digestive tract are distinct from those in the basolateral surface, leading to the different types of LPA signals to the gastrointestinal epithelium. Further extensive works on this aspect is needed to deepen our understanding of the physiological and pathophysiological effects of lysophospholipid mediators that act on the lumen side of the digestive system and for development of novel functional foods enriched in the lysophospholipids. Special care will be necessary because such lysophospholipid-enriched food supplements have the potential to aggravate gastrointestinal cancer. Also, systematic analysis of the concentrations of the lysophospholipids and its precursor diradyl-glycerophospholipids, in ordinary diets and different foodstuffs will be fruit- 
ful for providing a good indication of what type of foods are beneficial for human health judging from the effects helpful lysophospholipid mediators. Finally, the mechanisms of lysophospholipid production/degradation in the gastrointestinal tract and its movement through the digestive tract need to be actively investigated. These studies will provide useful information about how we prefer some foods in our daily diet, depending on our pathological states such as suffering from gastrointestinal ulcer or cancer.

Acknowledgements I thank Japan Science and Technology Agency for a grant of Research for Promoting Technological Seeds (13-042).

\section{REFERENCES}

1) Turner, J. R. (2009) Intestinal mucosal barrier function in health and disease. Nat. Rev. Immunol., 9, 799-809.

2) Rodriguez de Fonseca, F., Navarro, M., Gomez, R., Escuredo, L., Nava, F., Fu, J., Murillo-Rodriguez, E., Giuffrida, A., LoVerme, J., Gaetani, S., Kathuria, S., Gall, C. and Piomelli, D. (2001) An anorexic lipid mediator regulated by feeding. $\mathrm{Na}$ ture, 414, 209-212.

3) Fu, J., Astarita, G., Gaetani, S., Kim, J., Cravatt, B. F., Mackie, K. and Piomelli, D. (2007) Food intake regulates oleoylethanolamine formation and degradation in the proximal small intestine. J. Biol. Chem., 282, 1518-1528.

4) Sturm, A. and Dignass, A. U. (2002) Modulation of gastrointestinal wound repair and inflammation by phospholipids. Biochim. Biophys. Acta, 1582, 282-288.

5) Tokumura, A. (1995) A family of phospholipid autaocoids: occurrence, metabolism and bioactions. Prog. Lipid Res., 34, 151-184.

6) Noguchi, K., Herr, D., Mutoh, T. and Chun, J. (2009) Lysophosphatidic acid (LPA) and its receptors. Curr. Opin. Pharmacol., 9, 15-23.

7) Okudaira, S., Yukiura, H. and Aoki, J. (2010) Biological roles of lysophosphatidic acid signaling through its production by autotoxin. Biochimie, 92, 698-702.

8) Choi, J. W., Herr, D. R., Noguchi, K., Yung, Y. C., Lee, C. W., Mutoh, T., Lin, M. E., Teo, S. T., Park, K. E., Mosley, A. N. and Chun, J. (2010) LPA receptors: subtypes and biological actions. Annu. Rev. Pharmacol. Toxicol., 50, 157-186.

9) Okumura, S., Baba, H., Kumada, T., Nanmoku, K.,
Nakajima, H., Nakane, Y., Hioki, K. and Ikenaka, K. (2004) Cloning of a G-protein-coupled receptor that shows an activity to transform NIH3T3 cells and is expressed in gastric cancer cells. Cancer Sci., 95, 131-135.

10) Oka, S., Ota, R., Shima, M., Yamashita, A. and Sugiura, T. (2010) GPR35 is a novel lysophosphatidic acid receptor. Biochem. Biophys. Res. Commun., 395, 232-237.

11) Makide, K., Kitamura, H., Sato, Y., Okutani, M. and Aoki, J. (2008) Emerging lysophospholipid mediators, lysophosphatidylserine, lysophosphatidylthreonine, lysophosphatidylethanolamine and lysophosphatidylglycerol. Prostaglandins Other Lipid Mediat., 89, 135-139.

12) Choi, S., Lee, M., Shiu, A. L., Yo, S. J., Hallden, G. and Aponte, G. W. (2007) GPR93 activation by protein hydrolysate induces CCK transcription and secretion in STC-1 cells. Am. J. Physiol., 292, G1366-G1375.

13) Tomura, H., Mogi, C., Sato, K. and Okajima, F. (2005) Proton-sensing and lysolipid-sensitive Gprotein-coupled receptors: A novel type of multifunctional receptors. Cell. Signal., 17, 1466-1476.

14) Vesper, H., Schmelz, E.-M., Nikolova-Karakashian, M. N., Dillehay, D. L., Lynch, D. V. and Merrill, A. H., Jr. (1999) Sphingolipids in food and the emerging importance of sphingolipids to nutrition. J. Nutr., 129, 1239-1250.

15) Yunoki, K., Ogawa, T., Ono, J., Miyashita, R., Aida, K., Oda, Y. and Ohnishi, M. (2008) Analysis of sphingolipid classes and their contents in meals. Biosci. Biotechnol. Biochem., 72, 223-225.

16) Fischbeck, A., Krüger, M., Blaas, N. and Humpf, H.-U. (2009) Analysis of sphingomyelin in meat based on hydrophilic interaction liquid chromatography coupled to electrospray ionization-tandem mass spectrometry (HILIC-HPLC-ESI-MS/MS). J. Agric. Food Chem., 57, 9469-9474.

17) Duan, R. D. (2006) Alkaline sphingomyelinase: An old enzyme with novel implications. Biochim. Biophys. Acta, 1761, 281-291.

18) Duan, R. D. and Nilsson, A. (2009) Metabolism of sphingolipids in the gut and its relation to inflammation and cancer development. Prog. Lipid Res., 48, 62-72.

19) Schneider, M. (2001) Phospholipids for functional food. Eur. J. Lipid Sci. Technol., 103, 98-101.

20) Rombaut, R., Camp, J. V. and Dewettinck, K. (2005) Analysis of phospho- and sphingolipids in dairy products by new HPLC method. J. Dairy Sci., 88, 482-488.

21) Guo, Z., Vikbjerg, A. F. and Xu, X. (2005) Enzymatic modification of phospholipids for functional 
applications and human nutrition. Biotechnol. Adv., 23, 203-259.

22) Iqbal, J. and Hussain, M. M. (2009) Intestinal lipid absorption. Am J. Physiol., 296, E1183-E1194.

23) Hundrieser, K. and Clark, R. M. (1988) A method for separation and quantification of phospholipid classes in human milk. J. Dairy Sci., 71, 61-67.

24) Fang, N., Yu, S. and Badger, T. M. (2003) LCMS/MS analysis of lysophospholipids associated with soy protein isolate. J. Agric. Food Chem., 51, 6676-6682.

25) Tokumura, A., Fukuzawa, K., Akamatsu, Y., Yamada, S., Suzuki, T. and Tsukatani, H. (1978) Identification of vasopressor phospholipid in crude soybean lecithin. Lipids, 13, 468-472.

26) Nakane, S., Tokumura, A., Waku, K. and Sugiura, T. (2001) Hen egg yolk and white contain high amounts of lysophosphatidic acids, growth factorlike lipids: distinct molecular species compositions. Lipids, 36, 413-419.

27) Tanaka, T., Horiuchi, G., Matsuoka, M., Hirano, K., Tokumura, A., Koike, T. and Satouchi, K. (2009) Formation of lysophosphatidic acid, a wound-healing lipid, during digestion of cabbage leaves. Biosci. Biotechnol. Biochem., 73, 1293 1300.

28) Duncan, M., Thomas, A. D., Cluny, N. L., Patel, A., Patel, K. D., Lutz, B., Piomelli, D., Alexander, S. P. and Sharkey, K. A. (2008) Distribution and function of monoacylglycerol lipase in the gastrointestinal tract. Am. J. Physiol., 295, G1255G1265.

29) Richmond, B. L., Boileau, A. C., Zheng, S., Huggins, K. W., Granholm, N. A., Tso, P. and Hui, D. Y. (2001) Compensatory phospholipid digestion is required for cholesterol absorption in pancreatic phospholipase $\mathrm{A}_{2}$-deficient mice. Gastroenterology, 120, 1193-1202.

30) Takemori, H., Zolotaryov, F. N., Ting, L., Urbain, T., Komatsubara, T., Hatano, O., Okamoto, M. and Tojo, H. (1998) Identification of functional domains of rat intestinal phospholipase B/lipase. Its cDNA cloning, expression, and tissue distribution. J. Biol. Chem., 273, 2222-2231.

31) Huggins, K. W., Boileau, A. C. and Hui, A. D. (2002) Protection against diet-induced obesity and obesity-related insulin resistance in Group 1B $\mathrm{PLA}_{2}$-deficient mice. Am. J. Physiol., 283, E994E1001.

32) Labonte, E. D., Kirby, R. J., Schildmeyer, N. M., Cannon, A. M., Huggins, K. W. and Hui, D. Y. (2006) Group 1B phospholipase A2-mediated lysophospholipid absorption directly contributes to postprandial hyperglycemia. Diabetes, 55, 935941.

33) Nakano, T., Inoue, I., Katayama, S., Seo, M., Takahashi, S., Hokari, S., Shinozaki, R., Hatayama, K. and Komoda, T. (2009) Lysophosphatidylcholine for efficient intestinal lipid absorption and lipoprotein secretion in Caco-2 cells. $J$. Clin. Biochem. Nutr., 45, 227-234.

34) Nishimukai, M., Wakisaka, T. and Hara, H. (2003) Ingestion of plasmalogen markedly increased plasmalogen levels of blood plasma in rats. Lipids, $\mathbf{3 8}$, 1227-1235.

35) Kono, M., Dreier, J. L., Ellis, J. M., Allende, M. L., Kalkofen, D. N., Sanders, K. M., Bielawski, J., Bielawska, A., Hannun, Y. A. and Proia, R. L. (2006) Neutral ceramidase encoded by the Asah2 gene is essential for the intestinal degradation of sphingolipids. J. Biol. Chem., 281, 7324-7331.

36) Furuya, H., Ohkawara, S., Nagashima, K., Asanuma, N. and Hino, T. (2008) Dietary sphingomyelin alleviates experimental inflammatory bowel disease in mice. Int. J. Vitam. Nutr. Res., 78, 41-49.

37) Soo, I., Madsen, K. L., Tejpar, Q., Sydora, B. C., Sherbaniuk, R., Cinque, B., Di Marzio, L., Cifone, M. G., Desimone, C. and Fedr'rak, R. N. (2008) VSL\#3 probiotic upregulates intestinal mucosal alkaline sphingomyelinase and reduced inflammation. Can. J. Gastroenterol., 22, 237-242.

38) Ehehalt, R., Jochims, C., Lehmann, W. D., Erben, G., Staffer, S., Reininger, C. and Stremmel, W. (2004) Evidence of luminal phosphatidylcholine secretion in rat ileum. Biochim. Biophys. Acta, 1482, 63-71.

39) Treede, I., Braun, A., Jeliaskova, P., Giese, T., Fullekrug, J., Griffths, G., Stremmel, R. and Ehehelt, R. (2009) TNF- $\alpha$-induced up-regulation of pro-inflammatory cytokines is reduced by phosphatidylcholine in intestinal epithelial cells. $B M C$ Gastroenterology, 9, 53.

40) Langton, S. R. and Cesareo, S. D. (1992) Helicobacter pylori associated phospholipase $\mathrm{A}_{2}$ activity: a factor in peptic ulcer production? J. Clin. Pathol., 45, 221-224.

41) Demirbilek, S., Gürses, I., Sezgin, N., Karaman, A. and Gürbüz, N. (2004) Protective effect of polyunsaturated phosphatidylcholine pretreatment on stress ulcer formation in rats. J. Pediatr. Surg., 39, 57-62.

42) Dunjic, B. S., Axelson, J., Ar'Rajab, A., Larsson, K. and Bengmark, S. (1993) Gastroprotective capability of exogenous phosphatidylcholine in experimentally induced chronic gastric ulcers in rats. 
Scand. J. Gastroenterol., 28, 89-94.

43) Fabia, R., Ar'Rajab, A., Willen, R., Andersson, R., Ahren, B., Larsson, K. and Bengmark, S. (1992) Effects of phosphatidylcholines and phosphatidylinositols on acetic acid-induced colitis in the rat. $\mathrm{Di}$ gestion, 53, 35-44.

44) Dial, E. J., Rooijakkers, S. H. M., Darling, R. L., Romero, J. J. and Lichtenberger, L. M. (2007) Role of phosphatidylcholine saturation in preventing bile salt toxicity to gastrointestinal epithelia and membranes. Gastroenterology, 23, 430-436.

45) Mourelle, M., Guarner, F. and Malagelada, J. R. (1996) Polyunsaturated phosphatidylcholine prevents stricture formation in a rat model of colitis. Gastroenterology, 110, 1093-1097.

46) Darling, R. L., Romero, J. J., Dial, E. J., Akunda, J. K., Langenbach, R. and Lichtenberger, L. M. (2004) The effects of aspirin on gastric mucosal integrity, surface hydrophobicity and prostaglandin metabolism in cycloxygenase knockout mice. Gastroenterology, 127, 94-104.

47) Ehehalt, R., Wagenblast, J., Erben, G., Lehmann, W. D., Hinz, U., Merle, U. and Stremmel, W. (2004) Phosphatidylcholine and lysophosphatidylcholine in intestinal mucus of ulcerative colitis patients. A quantitative approach by nanoelectrospray-tandem mass spectrometry. Scand. J. Gastroenterol., 39, 737-742.

48) Stremmel, W., Merle, U., Zahn, A., Autschbach, F., Hinz, U. and Ehehalt, R. (2005) Retarded release phosphatidylcholine benefits patients with chronic active ulcerative colitis. Gut, 54, 966-971.

49) Treede, I., Braun, A., Sparla, R., Kühnel, M., Giese, T., Turner, J. R., Anes, E., Kulaksiz, H., Füllekrung, J., Stremmel, R., Griffiths, G. and Ehehalt, R. (2007) Anti-inflammatory effects of phosphatidylcholines. J. Biol. Chem., 282, 2715527166.

50) Parlesak, A., Schaeckeler, S., Moser, L. and Bode, C. (2007) Conjugated primary bile salts reduce permeability of endotoxin through intestinal epithelial cells and synergize with phosphatidylcholine in intestinal epithelial cells, Crit. Care Med., 35, 2367-2374.

51) Persson, E. M., Nilsson, R. G., Hansson, G. I., Löfgren, L. J., Liback, F., Knutson, L., Abrahamsson, B. and Lennernäs, H. (2006) A clinical single-pass perfusion investigation of the dynamics in vivo secretory response to dietary meal in human proximal small intestine. Pharm. Res., 23, 742-751.

52) Zayat, M., Lichtenberger, L. M. and Dial, E. J. (2008) Pathophysiology of LPS-induced gastroin- testinal injury in the rat: role of secretory phospholipase $\mathrm{A}_{2}$. Shock, 30, 206-211.

53) Nakano, T., Inoue, I., Alpers, D. H., Akiba, Y., Katayama, S., Shinozaki, R., Kaunitz, J. D., Ohshima, S., Akita, M., Takahashi, S., Koyama, I., Matsushita, M. and Komoda, T. (2009) Role of lysophosphatidylcholine in brush-border intestinal alkaline phosphatase release and restoration. Am. J. Physiol., 297, G207-G214.

54) Maksem, J., Jacbson, N. and Neiderhiser, D. H. (1984) Lysophosphatidylcholine-induced gastric injury and ulceration in the guinea pig. Am. J. Pathol., 115, 288-295.

55) Neiderhiser, D. H. and Maksem, J. (1987) Gastric mucosal damage induced by combination of ethanol and lysophosphatidylcholine. Dig. Dis. Sci., 32, 628-640.

56) Dial, E. J., Tran, D. M., Romero, J. J., Zayat, M. and Lichtenberger, L. M. (2009) A direct role for secretory phospholipase $\mathrm{A}_{2}$ and lysophosphatidylcholine in the mediation of LPS-induced gastric injury. Shock, 33, 634-638.

57) Kajander, K., Myllyluoma, E., Kyrönpalo, S., Rasmussen, M., Sipponen, P., Mattila, I., Seppönen-Laakso, T., Vapaatalo, H., Oresic, M. and Korpela, R. (2009) Elevated pro-inflammatory and lipotoxic mucosal lipids characterize irritable bowel syndrome. World J. Gastroenterol., 15, 6068-6074.

58) Surrel, F., Jemel, I., Boilard, E., Bollinger, J. G., Payre, C., Mounier, C. M., Talvinen, K. A., Laine, V. J. G., Nevalainen, T. J., Gelb, M. H. and Lambeau, G. (2009) Group X phospholipase $A_{2}$ stimulates the production of colon cancer cells by producing of various lipid mediators. Mol. Pharmacol., 76, 778-790.

59) Sparkes, B. L., Slone, E. E. A., Roth, M., Welti, R. and Fleming, S. D. (2010) Intestinal lipid alterations occur prior to antibody-induced prostaglandin E2 production in a mouse model of ischemic/reperfusion. Biochim. Biophys. Acta, 1801, 517-525.

60) Tagesson, C., Franzén, L., Dahl, G. and Weström, B. (1985) Lysophosphatidylcholine increases rat ileal permeability to macromolecules. Gut, 26, 369-377.

61) Karlqvist, P. A., Franzen, L., Sjödahl, R. and Tagesson, C. (1986) A study of the permeability of rat stomach to larger molecules. Influence of lysophosphatidylcholine. Acta Chir. Scand, 152, 279-284.

62) Otamiri, T., Sjödahl, R. and Tagesson, C. (1986) Lysophosphatidylcholine potentiates the increase 
in mucosal permeability after small-intestinal ischemia. Scand. J. Gastroenterol., 21, 1131-1136.

63) Talbot, R. W., Foster, J. R., Hermon-Taylor, J. and Grant, D. A. (1984) Induced mucosal penetration and transfer to portal blood of luminal horseradish peroxidase after exposure of mucosa of guineapig small intestine to ethanol and lysolecithin. Dig. Dis. Sci., 29, 1015-1022.

64) Sawai, T., Lampman, R., Hua, Y., Segura, B., Drongowski, R. A., Coran, A. G. and Harmon, C. M. (2002) Lysophosphatidylcholine alters enterocyte monolayer permeability via a protein kinase $\mathrm{C} / \mathrm{Ca}^{2+}$ mechanism. Pediatr. Surg. Int., 18, 591594.

65) Yan, J. J., Jung, J. S., Lee, J. E., Lee, J., Huh, S. O., Kim, H. S., Jung, K. C., Cho, J. Y., Nam, J. S., Suh, H. W., Kim, Y. H. and Song, D. K. (2004) Therapeutic effects of lysophosphatidylcholine in experimental sepsis. Nat. Med., 10, 161-167.

66) Ottlecz, A., Romero, J. J. and Lichtenberger, L. M. (2001) Helicobacter infection and phospholipase A2 enzymes: Effect of Helicobacter felis-infection on the expression and activity of sPLA2 enzymes in mouse stomach. Mol. Cell. Biochem., 221, 7177.

67) Sakata, T., Nakamura, E., Tsuruta, Y., Tamaki, M., Teraoka, H., Tojo, H., Ono, T. and Okamoto, M. (1989) Presence of pancreatic-type phospholipase A2 mRNA in rat gastric mucosa and lung. Biochim. Biophys. Acta, 1009, 124-126.

68) Almer, S., Franzen, L., Olaison, G., Smedh, K. and Strom, M. (1991) Phospholipase $A_{2}$ activity of colonic mucosa in patients with ulcerative colitis. Digestion, 50, 135-141.

69) Minami, T., Tojo, H., Shinomura, Y., Matsuzawa, Y. and Okamoto, M. (1994) Increased group II phospholipase A2 in colonic mucosa of patients with Crohn's disease and ulcerative colitis. Gut, 35, 1593-1598.

70) Watanabe, T., Ohara, S., Ichikawa, T., Saigenji, K. and Hotta, K. (1996) Mechanisms for cytoprotection by vitamin $\mathrm{U}$ from ethanol-induced gastric mucosal damage in rats. Dig. Dis. Sci., 41, 49-54.

71) Aoki, J., Inoue, A. and Okudaira, S. (2008) Two pathways for lysophosphatidic acid production. Biochim. Biophys. Acta, 1781, 543-548.

72) Mounier, C. M., Wendum, D., Greenspan, E., Flejou, J. F., Rosenberg, D. W. and Lambeau, G. (2008) Distinct expression pattern of the full set of secreted phospholipase $\mathrm{A}_{2}$ in human colorectal adenocarcinomas: sPLA2-III as biomarker candidate. Br. J. Cancer, 98, 587-595.

73) Tokumura, A., Harada, K., Fukuzawa, K. and
Ttsukatani, H. (1986) Involvement of lysophospholipase D in the production of lysophosphatidic in rat plasma. Biochim. Biophys Acta, 875, 31-38.

74) Tokumura, A. (2002) Physiological and pathophysiological roles of lysophosphatidic acids produced by secretory lysophospholipase D in body fluids. Biochim. Biophys. Acta, 1582, 18-25.

75) Tokumura, A. (2004) Metabolic pathways and physiological and pathological significance of lysolipid phosphate mediator. J. Cell. Biochem., 92, 869-881.

76) Nakanaga, K., Hama, K. and Aoki, J. (2010) Autotaxin-an LPA producing enzyme with diverse functions. J. Biochem. (Tokyo), 148, 13-24.

77) Stracke, M. L., Krutzsch, H. C., Unsworth, E. J., Årestad, A., Cioce, V., Schiffmann, E. and Liotta, L. A. (1992) Identification, purification, and partial sequence analysis of autotoxin, a novel motilitystimulating protein. J. Biol. Chem., 267, 25242529.

78) Tokumura, A., Majima, E., Kariya, Y., Tominaga, K., Kogure, K., Yasuda, K. and Fukuzawa, K. (2002) Identification of human plasma lysophospholipase D, a lysophosphatidic acid-producing enzyme, as autotoxin, a multifunctional phosphodiesterase. J. Biol. Chem., 277, 39436-39442.

79) Umezu-Goto, M., Kishi, Y., Taira, A., Hama, K., Dohmae, N., Takio, K., Yamori, T., Mills, G. B., Inoue, K., Aoki, J. and Arai, H. (2002) Autotaxin has lysophospholipase D activity leading to tumor cell growth and motility by lysophosphatidic acid production. J. Cell Biol., 158, 227-233.

80) Khurana, S., Tomar, A., George, S. P., Wang, Y., Siddiqui, R., Guo, H., Tigyi, G. and Mathew, S. (2008) Autotaxin and lysophosphatidic acid stimulate intestinal cell motility by redistribution of the actin modifying protein villin to the developing lamellipodia. Exp. Cell Res., 314, 530-542.

81) Ishihara, R., Tatsuta, M., Iishi, H., Baba, M., Uedo, N., Higashino, K., Mukai, M., Ishiguro, S., Kobayashi, S. and Murofushi-Murakami, K. (2004) Attenuation by cyclic phosphatidic acid of peritoneal metastasis of azoxymethane-induced intestinal cancers in Wistar rats. Int. J. Cancer, 110, 188-193.

82) Baker, D. L., Fujiwara, Y., Pigg, K. R., Tsukahara, R., Kobayashi, S., Murofushi, H., Uchiyama, A., Murakami-Murofushi, K., Koh, E., Bandle, R. W., Byun, H. S., Bittman, R., Fan, D., Murph, M. M., Mills, G. B. and Tigyi, G. (2006) Carba analogs of cyclic phosphatidic acid are selective inhibitors of autotoxin and cancer cell invasion and metastasis. J. Biol. Chem., 281, 22786-22793. 
83) Funk-Archelta, M. A., Foehr, M. W., Tomei, L. D., Hennebold, K. L. and Bathurst, I. C. (1997) Soy-derived antiapoptotic fraction decreases methotrexate toxicity in the gastrointestinal tract of the rat. Nutr. Cancer, 29, 217-221.

84) Sturm, A., Becker, A., Schulte, K. M., Goebell, H. and Dignass, A. U. (1999) Lysophosphatidic acid modulates intestinal epithelial cell function in vitro by lysophosphatidic acid. Gasteroenterology, 117, 368-377.

85) Sturm, A., Zeeh, J., Sudermann, T., Rath, H., Gerken, G. and Dignass, A. U. (2002) Lisofylline and lysophospholipids ameliorate experimental colitis in rats. Digestion, 66, 23-29.

86) Minami, T., Tojo, H., Zushi, S., Shinomura, Y. and Matsuzawa, Y. (1997). Phospholipase $A_{2}$ stimulates rat gastric epithelial cell line (RGM-1) migration. Inflamm. Res., 46, 103-107.

87) Bhowmik, A., Paimela, H., Mustonen, H. and Kivilaakso, E. (2002) Roles of cytoskeleton and tyrosine receptor mediated signal transduction in the restitution of isolated guinea-pig gastric mucosa. Scand. J. Gastroenterol., 37, 759-764.

88) Adachi, M., Horiuchi, G., Ikematsu, N., Tanaka, T., Terao, J., Satouchi, K. and Tokumura, A. (2011) Intragastrically administrated lysophosphatidic acids protect against gastric ulcer in rats under water-immersion restraint stress. Dig. Dis. Sci., DOI 10.1007/S16620-011-19595-0

89) Li, C., Dandridge, K. S., Di, A., Marrs, K. L., Harris, E. L., Roy, K., Jackson, J. S., Makarowa, N. V., Fujiwaha, Y., Farrar, P. L., Nelson, D. J., Tigyi, G. J. and Naren, A. P. (2005) Lysophosphatidic acid inhibits cholera toxin-induced secretory diarrhea through CFTR-dependent protein interations. J. Exp. Med., 202, 975-986.

90) Singh, A. K., Riederer, B., Krabbenhöft, A., Rausch, B., Bonhagen, J., Lehmann, U., de Jonge, H. R., Donowitz, M., Yun, C., Weinman, E. J., Kocher, O., Hogema, B. M. and Seidler, U. (2009) Differential roles of NHERF1, NHERF2, and PDZK1 in regulating CFTR-mediated intestinal anion secretion in mice. J. Clin. Invest., 119, 540-549.

91) Lin, S., Yeruva, S., He, P., Singh, A. K., Zhang, H., Chen, M., Lamprecht, G., de Jonge, H. R., Tse, M., Donowitz, M., Hogema, B. M., Chun, J., Seidler, U. and Yun, C. C. (2010) Lysophosphatidic acid stimulates the intestinal brush border $\mathrm{Na}^{+} / \mathrm{H}^{+}$exchanger and fluid absorption via LPA5 and NHERF2. Gastroenterology, 138, 649-658.

92) Singla, A., Dwivedi, A., Saksena, S., Gill, R. K., Alrefai, W. A., Ramaswamy, K. and
Dudeja, P. K. (2010) Mechanisms of lysophosphatidic acid (LPA) mediated stimulation of intestinal apical $\mathrm{Cl}^{-} / \mathrm{OH}^{-}$exchange. Am. J. Physiol., 298, G182-G189.

93) Cha, B., Zhu, X. C., Chen, W., Jones, M., Ryoo, S., Zachos, N. C., Chen, T. E., Lin, R., Sarker, R., Kenworthy, A. K., Tse, M., Kovbasnjuk, O. and Donowitz, M. (2010) NHE3 mobility in brush borders increases upon NHERF2-dependent stimulation by lysophosphatidic acid. J. Cell Sci., 123, 2434-2443.

94) Rusovici, R., Ghaleb, A., Shim, H., Yang, V. W. and Yun, C. C. (2007) Lysophosphatidic acid prevents apoptosis of Caco-2 colon cancer cells via activation of mitogen-activated protein kinase and phosphorylated of Bad. Biochim. Biophys. Acta, 1770, 1194-1203.

95) Lin, S., Lee, S. J., Shim, H., Chun, J. and Yun, C. C. (2010) The absence of LPA receptor 2 reduces the tumorigenesis by ApcMin mutation in the intestine. Am. J. Physiol., 299, G1128-G1138.

96) Deng, W., Shuyu, E., Tsukahara, R., Valentine, W. J., Durgam, G., Gududuru, V., Balazs, L., Manickam, V., Arsura, M., Vanmiddlesworth, L., Johnson, L. R., Parrill, A. L., Miller, D. D. and Tigyi, G. (2007) The lysophosphatidic acid type 2 Receptor is required for protection against radiation-induced intestinal injury. Gastroenterology, 132, 1834-1851.

97) Shida, D., Kitayama, J., Yamaguchi, H., Okaji, Y., Tsuno, N. H., Watanabe, T., Takuwa, Y. and Nagawa, H. (2003) Lysophosphatidic acid (LPA) enhances the metastatic potentials of human colon carcinoma DLD1 cells through LPA1. Cancer Res., 63, 1706-1711.

98) Lin, S., Wang, D., Iyer, S., Ghaleb, A. M., Shim, H., Yang, V. W., Chun, J. and Yun, C. C. (2009) The absence of $\mathrm{LPA}_{2}$ attenuates tumor formation in an experimental model of colitisassociated cancer. Gastroenterology, 136, 17111720.

99) Lee, C. W., Rivera, R., Gardell, S., Dubin, A. E. and Chun, J. (2006) GPR92 as a new $\mathrm{G}_{12 / 13^{-}}$and $\mathrm{G}_{\mathrm{q}}$-coupled lysophosphatidic acid receptor that increases cAMP; LPA 5 . J. Biol. Chem., 281, 2358923597.

100) Kotarsky, K., Boketoft, A., Bristulf, J., Nilsson, N. E., Norberg, A., Hansson, S., Owman, C., Sillard, R., Leeb-Lundberg, L. M. F. and Olde, B. (2006) Lysophosphatidic acid binds to and activates GPR92, a G protein-coupled receptor highly expressed in gastrointestinal lymphpcytes. J. Pharmacol. Exp. Ther., 318, 619-628. 
101) Lee, M., Choi, S., Halldén, G., Yo, S. J., Schichnes, D. and Aponte, G. W. (2009) P2Y5 is $\mathrm{G} \alpha \mathrm{i}, \mathrm{G} \alpha 12 / 13 \mathrm{G}$ protein-coupled receptor activated by lysophosphatidic acid that reduces intestinal cell adhesion. Am. J. Physiol., 297, G641G654.

102) Tatsuta, M., Iishi, H., Baba, M., Uedo, N., Ishihara, R., Higashino, K., Mukai, M. and Ishiguro, S. (2005) Induction by lysophosphatidic acid of peritoneal and pleural metastased of intestinal cancers induced by azoxymethane in Wistar rats. Cancer Lett., 219, 137-145.

103) Shida, D., Watanabe, T., Aoki, J., Hama, K., Kitayama, J., Sonoda, H., Kishi, Y., Yamaguchi, H., Sasaki, S., Sako, A., Konishi, T., Arai, H. and Nagawa, H. (2004) Aberrant expression of lysophosphatidic acid (LPA) receptors in human colorectal cancer. Lab. Invest., 84, 1352-1362.

104) Lee, S. J. and Yun, C. C. (2010) Colorectal cancer cells-Proliferation, survival and invasion by lysophosphatidic acid. Int. J. Biochem. Cell Biol., 42, 1907-1911.

105) Yamashita, H., Kitayama, J., Shida, D., Ishikawa, M., Hama, K., Aoki, J., Arai, H. and Nagawa, H. (2006) Differential expression of lysophosphatidic acid receptor- 2 in intestinal and diffuse type gastric cancer. J. Surg. Oncol., 93, 30-35.

106) Kim, M. H., Park, J. S., Chang, H. J., Baek, M. K., Kim, H. R., Shin, B. A., Ahn, B. W. and Jung, Y. D. (2008) Lysophosphatidic acid promotes cell invasion by up-regulation the urokinase-type plasminogen activator in human gastric cancer cells. $J$. Cell. Biochem., 104, 1102-1112.
107) Thamilselvan, V., Li, W., Sumpio, B. E. and Basson, M. D. (2002) Sphingosine-1-phosphate stimulates human Caco-2 intestinal epithelial proliferation via $\mathrm{p} 38$ activation and activates ERK by an independent mechanism. In Vitro Cell. Dev. Biol. Anim., 38, 246-253.

108) Snider, A. J., Kawamori, T., Bradshaw, S. G., Orr, K. A., Gilkeson, G. S., Hannun, Y. A. and Obeid, L. M. (2009) A role for sphingosine kinae 1 in dextran sulfate sodium-induced colitis. FASEB J., 23, 143-152.

109) Greenspon, J., Li, R., Xiao, L., Rao, J. N., Marasa, B. S., Strauch, E. D., Wang, J. Y. and Turner, D. J. (2009) Sphingosine-1-phosphate protects intestinal epithelial cells from apoptosis through the Akt signaling pathway. Dig. Dis. Sci., 54, 499-510.

110) Prestwich, G. D., Gajewiak, J., Zhang, H., Xu, X., Yang, G. and Serban, M. (2008) Phosphataseresistant analogues of lysophosphatidic acid agonists promote healing antagonists and autotoxin inhibitors treat cancer. Biochim. Biophys. Acta, 1781, 588-594.

111) Parrill, A. L. and Baker, D. L. (2008) Autotaxin inhibitions: challenges and progress toward novel anti-cancer agents. Anticancer Agents Med. Chem., 8, 917-923.

112) Ueda, K., Yoshioka, M., Yoshihara, M., Nakao, M., Tanaka, T., Sano, S., Fukuzawa, K. and Tokumura, A. (2010) Evaluation of inhibitory action of flavonols and related substances on lysophospholipase D activity of serum autotoxin by a convenient assay using a chromogenic substrate. J. Agric. Food Chem., 58, 6053-6063. 